\title{
Linking the incidence and age patterns of clinical malaria to parasite prevalence using a mathematical model
}

\author{
Jamie T Griffin*, Neil M Ferguson, Azra C Ghani \\ From Challenges in malaria research \\ Basel, Switzerland. 10-12 October 2012
}

\section{Background}

Estimating the changing burden of malaria disease remains difficult due to limitations in health reporting systems in those countries with the largest burden of disease. Methods extrapolating from parasite prevalence data are therefore often employed.

\section{Materials and methods}

We present an approach to estimating disease incidence from prevalence data accounting for the changing age distribution of cases that occurs as transmission declines. We use a transmission model to capture the shifting agepattern of disease at different transmission intensities through dynamically modelling the acquisition and loss of immunity. The model is fitted to age-stratified data on the incidence of uncomplicated malaria due to Plasmodium falciparum from 24 sites in 9 sub-Saharan African countries. We used Bayesian methods, and accounted for variation in treatment rates and reporting methods (active versus passive case detection).

\section{Results}

We estimate that passive case detection picks up 33\% (95\% credible interval ( $\mathrm{Crl}): 19-59 \%)$ as many cases as daily active detection, and weekly detection $76 \%$ as many (95\% Crl: 61-88\%). However, there was wide variation in incidence between studies that cannot be explained by differences in case-finding or case definitions such as parasitaemia thresholds, and so substantial uncertainty remains in the incidence at any given transmission intensity. We estimate that at a parasite prevalence in 2 to 10 year-olds of $60 \%, 55 \%$ of cases occur in under-fives and

\footnotetext{
MRC Centre for Outbreak Analysis \& Modelling, Department of Infectious Disease Epidemiology, Imperial College London, UK
}

$14 \%$ in over $15 \mathrm{~s}$; at a prevalence of $20 \%, 21 \%$ are in under-fives and $41 \%$ are in over $15 \mathrm{~s}$; and at a prevalence of $5 \%, 10 \%$ are in under-fives and $60 \%$ in over $15 \mathrm{~s}$.

\section{Conclusion}

These estimates allow us to predict the incidence of clinical malaria in any age group, based on an estimate of the parasite prevalence in a possibly different age range. As the results are based on a transmission model, we can also predict the impact of interventions on incidence and its age pattern.

Published: 15 October 2012

doi:10.1186/1475-2875-11-S1-P115

Cite this article as: Griffin et al:: Linking the incidence and age patterns of clinical malaria to parasite prevalence using a mathematical model. Malaria Journal 2012 11(Suppl 1):P115.
Submit your next manuscript to BioMed Central and take full advantage of:

- Convenient online submission

- Thorough peer review

- No space constraints or color figure charges

- Immediate publication on acceptance

- Inclusion in PubMed, CAS, Scopus and Google Scholar

- Research which is freely available for redistribution
C Biomed Central
(C) 2012 Griffin et al; licensee BioMed Central Ltd. This is an Open Access article distributed under the terms of the Creative Commons Attribution License (http://creativecommons.org/licenses/by/2.0), which permits unrestricted use, distribution, and reproduction in any medium, provided the original work is properly cited. 